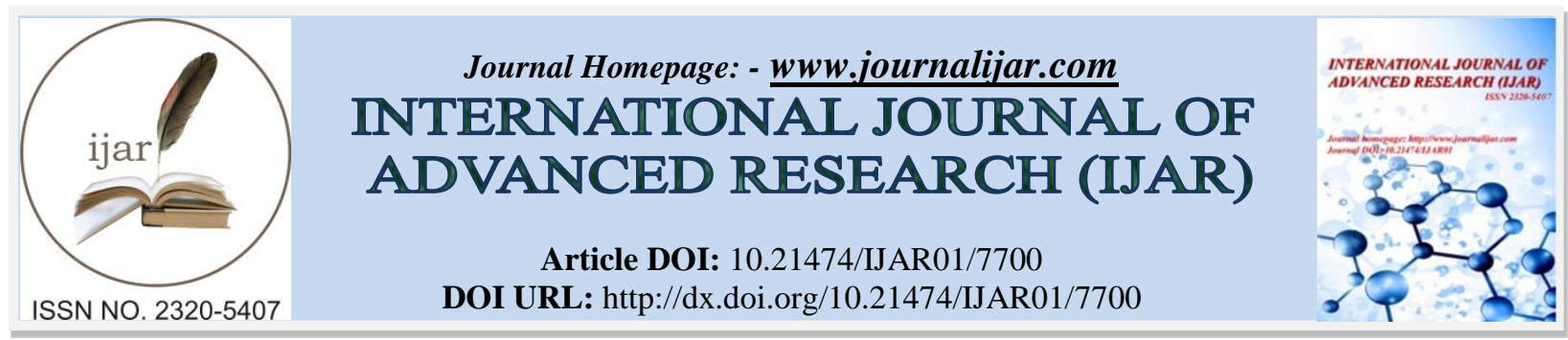

RESEARCH ARTICLE

\title{
WORK-LIFE BALANCE AMONG WOMEN NURSING EMPLOYEES IN THE HEALTHCARE SECTOR; ROLE OF GENDER DISCRIMINATION AND ORGANIZATIONAL COMMITMENT WITH SPECIAL REFERENCE TO NORTH KERALA.
}

Sivaprasad. K. $\mathrm{I}^{\mathbf{1}}$ and Dr. P. T. Raveendran ${ }^{2}$.

1. Research Scholar, Department of Management Studies; Kannur University, Kerala.

2. Professor, Department of Management Studies; Kannur University, Kerala.

\section{Manuscript Info}

\section{Manuscript History}

Received: 19 July 2018

Final Accepted: 25 August 2018

Published: September 2018

Keywords:-

Healthcare sector, Work-life balance,

Nurses, Gender Discrimination

Organizational commitment.

\begin{abstract}
Synchronous changes occurring in the pattern of work and family have impacted the work-life balance of individuals include nuclear families, single-parent families, and dual-earning parents, parents working at distant, different locations increasing household work in the current competitive scenario. Hence, balancing her work-related responsibilities and domestic responsibilities became difficult for women employees. So work-life balance of women employees' life has turned out to be a prominent topic in the society. Work-life balance refers to how effectively they divide their valuable time and effort inbetween two important domains such as work and life, of every employee. The purpose of this study was to assess the role of Gender discrimination and the level of organizational commitment in maintaining the satisfactory level of work-life balance. Data were collected using the self-constructed questionnaire. Data analysis consisted of Descriptive statistics, ANOVA's, Crosstab, and also correlation to find the result. The finding suggested that the respondents were satisfied with their current level of work-life balance. They are very much committed to their organization, which is highly contributing towards work-life balance but results showed that there is the less significant relationship between gender discrimination and work-life balance. Suggestion is, more rigorous action would be needed to spread the appropriate awareness among the employees about worklife balance policies and plans and try to communicate those things in a proper way to the employees to prevent work-life imbalance issues and untoward treatment towards a particular gender.it will help the organization to improve their commitment level and also productivity with good maintenance of work-life balance among employees including women.
\end{abstract}

Copy Right, IJAR, 2018, All rights reserved.

\section{Introduction:-}

The healthcare industry in India is one of the largest economic and fastest growing professions. Due to privatization in the healthcare sector in India, hospitals are confronting great competition; they are confronted with a variety of 
challenges posed by the business environment internally and externally. In order to create a balance between the provision and reception of health care, various strategies have been worked out which makes the industry effectively by health consciousness among people\& welfare schemes (Griffin; 2010). Nurses play the major role in the healthcare industry and are the first ones who are thought about when we talk about health care and thus it is necessary that their needs have to be taken care and a congenial atmosphere is created for them to work with utmost job satisfaction and content, the result of which would be a high-quality nursing care. Hospitals employees are also affected by workforce changes due to technological advancement and high rate of competition in this sector. Changes in the work style, work culture, Family needs, and work demands are rapidly taking place which eventually increased the population of dual-earner couples, single parent families and elder care responsibilities. These increased changes can have the adverse impact on employees as well as organizational performance. Increased pressure at workplace negatively affects the work-life balance, job satisfaction and organizational commitment (Kossek, 2005; Bragger et al, 2005; Anderson et al 2002).

However, in many countries, women still tend to be concentrated in the lower-status health occupations and to be a minority among more highly trained professionals. In particular, the distribution of women by occupational category tends to be skewed in favor of nursing and midwifery personnel and other 'caring' cadres such as community health workers. Women are often poorly represented in other categories, e.g. physicians, dentists, pharmacists, and managers. The under-representation of women in managerial and decision making positions may lead to less attention to and the poorer understanding of both the particular features of working conditions that characterize much of women's employment and the health care needs specific to women. In many contexts, access to female providers is an important determinant of women's health service utilization patterns. An omission of gender considerations may also lead to inadequate health system responsiveness to the needs of men: for example, reproductive health services are often not set up so as to encourage male involvement. Gender analysis of the health workforce may reveal that health systems themselves can reflect or even exacerbate many of the social inequalities they are meant to address and be immune from.

Work-life balance problem among Indian women nurses $42 \%$ of the estimated world paid working population belongs to women. It said that women section of gender is an indispensable contributor in the delivery of the healthcare services as they (women) comprised over $76 \%$ of the total workforce at healthcare sector in many world countries all over the world. (As per statistics on health workforce, World Health Organization). As a third world developing country, the picture is given by India never provides an edge of good hope as in the case of women empowerment, on the contrary, it shoots up the number of cases registered on account of assault and discrimination against women day by day. The under-representation of women in managerial and decision making positions may lead to lea attention to and the poorer understanding of both the particular features of working conditions that characterize much of women employees and the health care needs specific to women. For instance, the presence of women is predominant among midwifery and nursing professionals whereas it visible that less number of women working in another category likes Dentists, Pharmacists, physicians, and Managers.

Though Nursing is hailed as one of the noblest profession in the world, the women workforce in this category is afflicted with a lot of hardships. It is considered as most stressful and exceedingly difficult career. Today Indian nurses come across a number of problems like Exploitation, Lack of career development opportunities, shortage of trained nursing personnel, Migration to western countries etc. Hardly have they seen any scope for personal growth in their respective career. They forced to carry out of two to three employees work on an insignificant salary. Most of the hospitals working in the private sector do have not any fixed working hour, which set to be shuffled as per the management requirements. They cannot spend quality time with their family due to irregular inflexible working time policy. Disrespect from the colleagues, Doctors as well as some bystanders is also making some sort of stress because of their adamant or rude behavior. Hospitals are using unethical strategies to curtail the costs on account of salaries. It is severe exploitation is happening in the healthcare sector by appointing more nurses are in the name of trainees, by not providing adequate salaries or any increment to the women employees. Poor working conditions and hostel facilities haunting them, 5 to 6 person should have to reside in one single room, nevertheless, nurses are forced to stick on the current employment with an optimistic mind due to no other alternatives avail before them. The situations make more severe when the majority want to repay their respective educational loan within a stipulated period of time and also most of them come from poor background. This amount quite insufficient and no match between the loan amounts with their corresponding income. As Adam et al(1996) suggested in studies, the more level of work-load and the involvement on the work-related aspects, it is visible to see the higher the work-life conflict, subsequently which will lead to high level of labor turn over, burnout low satisfaction and also less degree 
of commitment. Owing to the above-mentioned reasons we can assume that they are in an acute work-family balance problem.

\section{Review of the literature.}

According to Gutek et al (1991), the two most important domains of life, such as work and family life are often in conflict due to stress generated from both family and work. Dual roles as a center of the family and a loyal subordinate, long hours of working, reduced presence at home, child illness, elder care, bring work-related stress to the family atmosphere etc. He is also said that the more preoccupied and reduced effectiveness due to that preoccupation, the higher the work-family conflict. Blaw and Boal (1987) had given a definition than organizational commitment is an identification of a loyalty toward the organization and also related to the individuality of an employee. A study conducted by Sakthivel \& Jayakrishnan (2012), Sakthivel \& Kamalanabhan (2011), reveals that there is a strong positive relationship between commitment, Work-life balance with productivity and performance at an organizational floor. According to cinnamon \& Rich (2005), there is a disproportionate level in the degree of conflict reported by the gender. In order to the increasing the experience, regardless of gender, work-life conflicts turn down. According to Wayne (1995), discrimination in the workforce context means giving an unfair advantage or disadvantage to the member $\mathrm{s}$ of a particular group in comparison to the members of the other group. Ivancevich (2003) commended that interpreting the title VII of the 1964 Civil Rights Act and other laws, the United States' courts have held that both intentional (disparate treatment) and unintentional (disparate impact) acts of covered entities may constitute illegal employment discrimination. Eric et al (2006) find in his study that women with feeding babies encounter larger gender penalties' in the career. The degree of discrimination faced by the employees more on in the initial years and also in the final stages of the career rather than the employees belongs to the midcareer stages. Susan et al (1998) opined that business men discriminated women and people at the top of the organization are most biased against the women employees than the people at the bottom. Another important finding has done by Habib (2000) in his study about effects of a brick wall and glass ceiling in public administration of Bangladesh, that Discrimination is not largely visible among the employees who come from the upper class of the society which affects the performance and motivational level as well as their morale to work .

\section{The rationale of the study}

The nursing profession in India is going through bad times. Many research studies share almost similar views that they are striving against adverse working conditions like shortage of trained nurses, disrespect from the society, poor working conditions, inadequate remuneration, and work overload, shortage of personnel, workplace restrictions, and also poor work-life balance. The intention of this study is to explore the role of organizational commitment and the gender discrimination on the perceived level of work-life balance among the female nurses in cooperative Academy of Medical science, Pariyaram, North Kerala, India.

\section{Research Methodology}

Research design proposed for the study is 'Descriptive' type of research service. The study is based on survey method, the primary data were collected about varied dimensions of work-life balance were through a suitably framed questionnaire among the women nursing employees in Cooperative Academy of Medical Science, Pariyaram situated at Kannur District in Northern Kerala. This type of research deals with the quality of responses from the respondents, behavioral, attitudes, commitment, experience, beliefs, Relationship status, emotions, personality, interests, and values etc. Primary data was collected through a survey method using the questionnaire as the tool. Secondary data was collected from journals and Research articles. Malayalam questionnaire was distributed among the respondents. The study was confined to the Academy of Medical science, Pariyaram; the sample size was fixed at 47 female nurses from various department s of the Academy of Medical Science, Pariyaram. The period of data collection was from September 2017 to October 2017. Likert's five-point scale was used to measure the experience and opinions of respondents to ascertain the level of work-life balance of nursing employees. Data collected have been presented in tabular form and the analysis has been done using frequency statistics, ANOVAs and Correlation.

\section{Objectives:-}

1. To understand more about the work-life balance issues of nursing employees who are working in healthcare industries.

2. To study about various dimensions of work-life balance issues which have been faced by women nursing employees in the healthcare industry.

3. To know the role of 'Gender discrimination' and 'organizational commitment' aspects on contributing the worklife balance of nursing employees. 


\section{Results and Discussion:- \\ Frequency Statistics}

$64.6 \%$ ether agrees or strongly agrees that women nursing employees need more support and consideration from the hospital management as well as society. But no gender discrimination issues raised by the respondents, which are $68 \%$ of the respondents either strongly, disagree or agree with the statement that is they were treated at par with opposite gender as in the case any work-related or behavior related issues. $96 \%$ of the employees who participated in the survey commented that they chose this career because of affinity with the nursing profession. $76.6 \%$ said the institution is so beloved to them because the institution facilitates better work-life balance maintenance. $63.8 \%$ employees disagree or strongly disagree with the statement that they more enjoy on official matters rather than the personal or family matters. $80.9 \%$ participants in a survey thought in such a way that the Academy of Medical Science has no such unique policy with regard to work-life balance of employees Nevertheless, $85.1 \%$ employees happy and satisfied with their level of current work-life balance.

Frequency Statistics (Mean standard deviation) statistics have given below with regard to the variables of work-life balance are presented in table number 1. All they are motivated because their affection towards their profession was so high (Mean score 4.23). But they love their family and they would like to spend quality time with their family (Mean score is 2.49) rather than the time they devoted for the sake of their work-related matters. But Irrespective of the facilities provided or policies framed which the organization, they love their mother institution. According to them (respondents), women labor jiggling in between work and family roles as she meets a lot of expectations from the society, so she deserves a serious consideration at workplaces irrespective of fields in which they are working (3.47 mean score). They told that, as far as this institution concerned no such incidents are reported at the workplace and moreover that, opportunities or benefits can avail for all irrespective of gender. Participants in the survey have shared their experience that the hospital could not frame a unique work-life balance policy for the sake of minimizing their work-life balance conflict (Mean score 2.15). Although they quite happy and also well satisfied with their level of current work-life balance maintenance.

Table No.1:-Frequency Statistics

\begin{tabular}{|l|l|l|l|}
\hline Variables & $\mathrm{N}$ & Mean & Std. Deviation \\
\hline Work commitment & 47 & 4.21 & .657 \\
\hline Work_life_policy & 47 & 2.15 & .884 \\
\hline WLB_OC & 47 & 3.83 & .868 \\
\hline Family_OC & 47 & 2.49 & .856 \\
\hline Gender_ & 47 & 2.45 & 1.119 \\
\hline Work_Life_Satisfaction & 47 & 3.85 & .780 \\
\hline Gender_discrimination & 47 & 3.47 & 1.080 \\
\hline
\end{tabular}

\section{Correlation}

Correlation analysis is a method of statistical evaluation used to understand the significance of relationships between two variables and establish the possible relationship between them. The main objective of the study is to find out the relationship between the variables such as organizational commitment and gender discrimination and also find how it contributes in work-life satisfaction of the employees who work in Academy of Medical Science. Correlation analysis was done to find out the relationship and its significance between 3 main variables such as Organizational commitment, Gender discrimination, and Work-life balance satisfaction. The results and analysis presented in table No.3. It is understood that there is a perfect positive correlation between Organizational commitment and work life satisfaction (At 0.01 significance level), meantime there is a negative relationship between Organizational commitment and Gender discrimination. It also stated that there is no significant relationship between Gender discrimination and work-life satisfaction. It shows high Organizational commitment vigorously contributes on well maintenance of work-life balance satisfaction whereas gender discrimination aspect is not significant enough for maintaining well work-life balance in this particular context.

Table No: 2:-Correlations

\begin{tabular}{|l|l|l|l|}
\hline Variables & Organizational Commitment & Gender Discrimination & W L B satisfaction \\
\hline Organizational Commitment & 1 & -.099 & $.508^{* *}$ \\
\hline Gender Discrimination & -.099 & 1 & -174 \\
\hline W L B satisfaction & $.508^{* *}$ & -246 & 1 \\
\hline
\end{tabular}




\section{** Significant at 0.01 level}

\section{Anova}

The One-way ANOVA facilitates you to determine the statistically significant differences between the means of two or more independent variables. Here an attempt has been made to establish the relationship between the variable work-life satisfaction and age or experiences. There no significant relationship was seen between any variables with independent variables such as age and experience.

\begin{tabular}{|l|l|l|l|}
\hline \multirow{2}{*}{ Independent variables } & Dependent Variables & Work-life satisfaction \\
\cline { 2 - 4 } & Gender Discrimination & OC & .359 \\
\hline Age & .778 & .956 & .929 \\
\hline Experience & .105 & .135 & \\
\hline
\end{tabular}

\section{Crosstab}

The cross-tabulation analysis reveals that 40 respondents out of 47 respondents are happy with the current work-life balance. Within that 40 respondent's 36 employees who participated in the survey either agree or strongly agree that they have inspired by a strong commitment towards their Mother institution. It is understood that organizational commitment aspect significantly contributes towards the work-life balance satisfaction than anything else.

\begin{tabular}{|c|c|c|c|c|c|c|c|}
\hline \multicolumn{8}{|c|}{ Cross-tabulation - Work-life Satisfaction and Organizational commitment } \\
\hline & & \multicolumn{5}{|c|}{ Work_Life_Satisfaction } & \multirow[t]{2}{*}{ Total } \\
\hline & & $\begin{array}{l}\text { Strongly } \\
\text { Dis } \\
\text { Agree }\end{array}$ & Disagree & $\begin{array}{l}\text { Neither } \\
\text { Agree } \\
\text { nor } \\
\text { Disagree }\end{array}$ & Agree & $\begin{array}{l}\text { Strongly } \\
\text { agree }\end{array}$ & \\
\hline \multirow[t]{5}{*}{ WLB_OC } & $\begin{array}{l}\text { Strongly Dis } \\
\text { Agree }\end{array}$ & 1 & 0 & 0 & 0 & 0 & 1 \\
\hline & Disagree & 0 & 1 & 0 & 2 & 0 & 3 \\
\hline & $\begin{array}{l}\text { Neither } \\
\text { Agree nor } \\
\text { Disagree }\end{array}$ & 0 & 0 & 3 & 3 & 1 & 7 \\
\hline & Agree & 0 & 2 & 0 & 24 & 2 & 28 \\
\hline & $\begin{array}{l}\text { Strongly } \\
\text { agree }\end{array}$ & 0 & 0 & 0 & 6 & 2 & 8 \\
\hline \multicolumn{2}{|l|}{ Total } & 1 & 3 & 3 & 35 & 5 & 47 \\
\hline
\end{tabular}

\section{Conclusion:-}

Work-life balance and organizational commitment are having the positive relationship. If nurses are having the good work-life balance, they are more committed to their organization. Hence, organizational should come forward to make their life is important and give due weight to personal factors. The organization should treat that their employees are as clients. Even more in today ever challenges environment that demands are balancing of both work and life responsibilities. The organization actively seek to improve employee morale, commitment, and job satisfaction as well as aiming at the reduced source of stress both at work and home through work-life balance policies. It will improve their ability to become the employer of choice as well as retain talent. In the nursing profession, becoming the employer of choice means that hospital practices employment terms and conditions are generous enough to attract employees away from their competitors and keep their own employees from learning the hospital.

\section{Managerial Implications}

The results of the current study have put forth a number of implications that have practical relevance for the authorities of these institutions. The hospital authorities need to consider the family aspect of their women employees, the steps like child care facilities, support for nurses who have aged parents, flexible working hours and 
sufficient time for relaxation etc. would help them to enhance their level of work-life balance maintenance. Management should take the necessary steps to spread awareness about their rights and work-life balance policies which is avail to them. The formal pragmatic strategy for communicating work-life policies should be essential. In Particular, to this group of employees, they are satisfied with the level of current life balance even though they had a little knowledge about it. Management should be capable to foresee the problems and cure it in advance. Irrespective of country or culture, the women face discrimination across the world. Management should be aware of the rights and privileges available to the women in particular and make them feel safe and secure at work sites. So management should take needful actions to prevent gender discrimination and behave in a compassionate way with special care and consideration to the need of the women employees. As far as women employees concerned they valued their organization utmost, management should take necessary steps to utilize their commitment in a favorable and healthy way which they can contribute the same for organizational, social development purpose. A scientific quality based selection of nursing employees in healthcare sector in general, ensure the quality service which will work as a mechanism to find solution for numerous work-life balance problems including reduce work overload, staff shortage and also reduce the level stress of the employees etc., which can utilize an imperative measure to reduce work-life imbalance problem of the employees.

\section{Limitations}

Only limited number of sample drawn among women employees of Cooperative Academy of Medical Science, Pariyaram, Kannur District, Kerala and so conclusions arrived at based on this study need to be placed in proper perspective before application elsewhere. Another limitation is that since the sample size is only 47 to ascertain whether women in different department face different challenges in balancing their work life.

\section{Research Gap}

The variables used in the research are not occupation specific and can be used to specify to assess the work-life balance policies in other professions also. In addition with, the focus group can be used to elicit more information on the importance of certain policies among other minority group or other categories of employees work in different types of hospitals in the Healthcare industry. Future investigations may include more policies of work-life balance and study in relation with organizational commitment, gender discrimination, more work related issues similar studies also can be conducted at different hospitals as well as in other cities etc.

\section{Reference:-}

1. Adams, G. A., King, L. A., \& King, D. W. (1996). Relationships of Job and Family Involvement, Family Social and Work-family Conflict with Job and Life Satisfaction. Journal of Applied Psychology, 81(4), 411-420.

2. Blau, G.J., Boal, K R. (1987).Conceptualizing how job involvement and organizational commitment affect turn over and absenteeism. The Academy of Management Review,21 (2),288-300

3. Cinamon, R.G\& Rich, Y. (2005).'Work -Family conflict among female teachers'. Teaching and Teacher Education, 21(4),365-378

4. Erik, Bihagen., Marita Ohls. (2006). the glass ceiling-where is it? Women's and men's career prospects in the private vs. the public sector in Sweden 1979-2000. The Sociological Review, 54(1), 20-47.

5. Gutek, B.A., Searle, S. and Klepa, L. (1991), "Rational versus gender role explanations for work-family conflict”, Journal of Applied Psychology, Vol. 76, pp. 560-8.

6. Habib, Zafarullah. (2000). Through the brick wall and the glass ceiling: women in the civil services in Bangladesh. Gender, Work and Organization, 7(3), 197-209

7. John, M. Ivancevich. (2004). Human Resource Management (9th edition). McGraw Hill, USA

8. M. L. Griffin, N. L. Hogan, E. G. Lambert, K. A. Tucker-Gail, and D. N. Baker, (2010), "Job involvement, job stress, job satisfaction, and organizational commitment and the burnout of correctional staff," Criminal Justice and Behavior, vol. 37, no. 2, pp. 239-255,

9. Sakthivel, D. \& Jayakrishnan, j. (2012) work-life balance and organizational commitment for nurses. Asian Journal of Business and Management Science, 2(5), 01-06

10. Sakthivel, R, Kamalanabhan, \& Selvarani. (2011). work-life balance reflections on employee satisfaction. Serbian Journal of Management 6(1):85-96

11. Susan, Trentham., Laurie, Larwood.(1998). Gender discrimination and the workplace: an examination of rational bias theory, Sex Roles. A Journal of Research, 38, 1-28.

12. Wayne, F. C. (1995). Managing human resource, productivity, quality of work life, Profits, McGraw Hill International (4th edition). 